\title{
Avaliação do consumo de proteínas e lipídios por homens jovens praticantes de musculação com tendência à dismorfia muscular
}

\author{
Assessment of proteins and lipids consumption by bodybuilders young men with a tendency to
} muscle dysmorphia

Evaluación de la ingesta de proteínas y lípidos en hombres jóvenes que practican el culturismo con tendencia a la dismorfia muscular

Recebido: 31/03/2021 | Revisado: 10/04/2021 | Aceito: 13/04/2021 | Publicado: 26/04/2021

\author{
Rafael Rocha Néri \\ ORCID: https://orcid.org/0000-0002-9086-8297 \\ Pontifícia Universidade Católica de Minas Gerais, Brasil \\ E-mail: rafaelnerinutricao@gmail.com \\ Nicolly Sulz de Oliveira Soares Mendes \\ ORCID: https://orcid.org/0000-0001-9692-3966 \\ Pontifícia Universidade Católica de Minas Gerais, Brasil \\ E-mail: sulzmendesnicolly@gmail.com \\ Ana Luiza Magalhães Silva \\ ORCID: https://orcid.org/0000-0002-9848-5071 \\ Pontifícia Universidade Católica de Minas Gerais, Brasil \\ E-mail: ana_lu@msn.com \\ Telma Teixeira Pereira \\ ORCID: https://orcid.org/0000-0001-6481-4490 \\ Pontifícia Universidade Católica de Minas Gerais, Brasil \\ E-mail: telmatp@hotmail.com
}

\begin{abstract}
Resumo
A dismorfia muscular (DM), também denominada de vigorexia ou Complexo de Adônis, é uma forma de transtorno dismórfico corporal que acomete principalmente homens adolescentes e jovens que creem que sua estrutura corporal seja muito pequena e insuficientemente musculosa. O objetivo deste trabalho foi identificar, entre praticantes de musculação matriculados em duas academias de ginástica da região metropolitana de Belo Horizonte, Minas Gerais, homens jovens com tendência à DM, e avaliar seu consumo diário de proteínas e lipídios. A amostra foi composta de 30 homens de 18 a 45 anos, praticantes de musculação há pelo menos um ano, com frequência mínima de três vezes na semana. Para identificar quais participantes possuíam tendência à DM, foi aplicado o Questionário do Complexo de Adônis. A avaliação do consumo alimentar foi feita mediante a aplicação de recordatório alimentar de 24 horas, no qual foram incluídos os suplementos alimentares ingeridos pelos entrevistados. 63,3\% dos participantes apresentaram tendência branda a moderada à DM e 6,7\% demonstraram tendência elevada. No que tange ao padrão dietético, $76,2 \%$ dos entrevistados com tendência à DM consumiam dietas hiperproteicas e 85,7\%, dietas hipolipídicas. Em relação ao consumo de suplementos alimentares, $71,4 \%$ dos participantes com tendência ao transtorno faziam uso dessas substâncias, dos quais 46,7\% não tinham acompanhamento nutricional. Reforçou-se a importância de os nutricionistas possuírem conhecimento sobre DM para identificar precocemente a tendência de seus pacientes a desenvolverem o transtorno, podendo definir os melhores métodos de abordagem terapêutica nutricional.
\end{abstract}

Palavras-chave: Transtorno dismórfico corporal; Dismorfia muscular; Complexo de Adônis; Vigorexia; Consumo alimentar.

\begin{abstract}
Muscle dysmorphia (MD), also denominated bigorexia or the Adonis Complex, is a form of body dysmorphic disorder that mainly affects teenagers and young men who believe that their body structure is too small and insufficiently muscular. The purpose of this work was to identify among bodybuilders registered in two gyms in the metropolitan region of Belo Horizonte, Minas Gerais, young men with a tendency to MD, and assess their daily consumption of proteins and lipids. The sample was composed of 30 men from 18 to 45 years old, bodybuilders for at least one year, with a minimum frequency of three times a week. To identify which participants presented a tendency to MD, an Adonis Complex Questionnaire was filled in. The assessment of the food consumption was made through the 24-hour food memory, in which was included the food supplement ingested by the interviewed. $63.3 \%$ of the participants presented mild to moderate tendency to $\mathrm{MD}$, and $6.7 \%$ demonstrated elevated tendency. $76.2 \%$ of the interviewed with a tendency to MD consumed hyper protein diets, and $85.7 \%$ hypo lipidic diets. Regarding the food
\end{abstract}


supplement consumption, $71.4 \%$ of the participants with a tendency to the disorder were using these substances, of which $46.7 \%$ did not have nutritional guidance. The importance of nutritionists with MD familiarity was reinforced to precociously identify among their patients the tendency to develop the disorder, making it possible the definition of the best methods of nutritional therapeutic approach.

Keywords: Body dysmorphic disorder; Muscle dysmorphia; Adonis complex; Bigorexia; Food consumption.

\section{Resumen}

La dismorfia muscular (DM), también llamada vigorexia o complejo de Adonis, es una forma de trastorno dismórfico corporal que afecta principalmente a los adolescentes y a los hombres jóvenes que creen que su estructura corporal es demasiado pequeña e insuficientemente musculada. El objetivo de este estudio fue identificar, entre los practicantes de musculación inscritos en dos centros de fitness de la región metropolitana de Belo Horizonte, a hombres jóvenes con tendencia a la DM, y evaluar su consumo diario de proteínas y lípidos. La muestra estaba compuesta por 30 hombres de entre 18 y 45 años, que habían practicado ejercicios con pesas durante al menos un año, con una frecuencia mínima de tres veces por semana. Para identificar qué participantes eran propensos a la DM, se aplicó el Cuestionario del Complejo de Adonis. La evaluación de la ingesta de alimentos se realizó aplicando un recordatorio de alimentos de 24 horas. El 63,3\% de los participantes mostraron una tendencia de leve a moderada a la DM y el $6,7 \%$ una tendencia alta. El 76,2\% de los entrevistados con tendencia a la DM consumían dietas hiperproteicas y el $85,7 \%$ dietas hipolipídicas. El $71,4 \%$ de los participantes con tendencia al trastorno utilizaba complementos alimenticios, de los cuales el $46,7 \%$ no tenía seguimiento nutricional. Se ha subrayado la importancia de que los nutricionistas tengan conocimientos sobre la DM para identificar con antelación la tendencia de sus pacientes a desarrollar el trastorno, pudiendo definir los mejores métodos de abordaje terapéutico nutricional.

Palabras clave: Trastorno dismórfico corporal; Dismorfia muscular; Complejo de Adonis; Vigorexia; Consumo de alimentos.

\section{Introdução}

Durante séculos, a preocupação excessiva com o corpo pareceu acometer exclusivamente mulheres. Entretanto, a busca exagerada pelo padrão físico ideal também passou a ser observada em indivíduos do sexo masculino, afetados por alterações psíquicas relacionadas à imagem corporal (Assunção, 2002; Ferreira et al., 2005).

Em um estudo realizado com 108 fisiculturistas, Pope Junior et al. (1993) constataram que nove participantes acreditavam aparentar-se pequenos e fracos, apesar de serem extremamente fortes e musculosos. Os pesquisadores inicialmente denominaram esse quadro de anorexia reversa. Contudo, após a realização de outras pesquisas sobre o assunto, Pope Junior et al. (1997) decidiram atribuir uma nova nomenclatura ao distúrbio, que passou a ser chamado de dismorfia muscular (DM), vigorexia ou Complexo de Adônis.

Conforme descrito na quinta edição do Manual Diagnóstico e Estatístico de Transtornos Mentais (DSM-5), a DM é uma forma de transtorno dismórfico corporal (TDC), de espectro obsessivo-compulsivo, que acomete principalmente homens adolescentes e jovens que creem que sua estrutura corporal seja muito pequena e insuficientemente musculosa (American Psychiatric Association, 2013/2014; Bonfim et al., 2016).

Ao contrário das mulheres, que desejam ficar magras e esguias, os homens buscam tornar-se cada vez mais fortes e musculosos, em virtude de esse modelo estar associado à imagem de masculinidade e virilidade (Cohane \& Pope Junior, 2001; Fernandes Filho, 2010; White et al., 2019).

No TDC, o indivíduo apresenta uma percepção distorcida da imagem corporal, preocupando-se com uma anomalia imaginária ou exagerada em relação a uma área específica do corpo (Bonfim et al., 2016). Diferentemente, na DM, o sujeito preocupa-se por não ser forte e musculoso em todas as partes do corpo, o que corresponde à principal característica do transtorno (Assunção, 2002).

Alguns autores defendem que os fatores socioculturais exercem um papel fundamental na origem da DM, tendo em vista que, na atualidade, a aparência física passou a significar sucesso e determinação (Bégin et al., 2019; Olivardia, 2001; Soler et al., 2013).

Grieve (2007) sustenta que a DM se origina da internalização de um padrão de corpo ideal, acrescida da distorção da 
imagem corporal e da insatisfação com o próprio corpo, potencializadas pelo perfeccionismo, baixa autoestima e fatores ambientais.

Chung (2001), ao tratar da influência da mídia, ressalta que a DM começou a ser notada a partir do momento em que revistas voltadas a praticantes de atividade física passaram a estampar celebridades exageradamente musculosas em suas capas, como Arnold Schwarzenegger e Sylvester Stallone. Atualmente, as redes sociais funcionam como vitrines de corpos perfeitos, por meio das quais influenciadores digitais compartilham fotos de músculos minuciosamente esculpidos, reforçando ainda mais esse parâmetro masculino de beleza (Alencar et al., 2020; Kotona et al., 2018; Velozo et al., 2020).

Não é mera coincidência que as academias de ginástica constituem um ambiente de concentração de pessoas com DM, configurando um mercado que movimenta anualmente 2,1 bilhões de dólares no Brasil, com 34,5 mil unidades instaladas no país, sendo 3.307 delas situadas em Minas Gerais (Assunção, 2002; Jornal Estado de Minas, 2019).

A DM está associada à prática exaustiva de treinamento de força e à adoção de padrões de alimentação específicos, compostos de dietas hiperproteicas e hipolipídicas, associadas ao uso indiscriminado de suplementos alimentares e esteroides anabolizantes, com o objetivo de aumentar a massa magra e reduzir a gordura corporal (Contesini et al., 2013).

Treinamentos excessivos, associados à falta de intervalo de descanso para recuperação, podem resultar em fadiga, lesões e overtraining, comprometendo ainda mais a qualidade de vida desses indivíduos (Azevedo et al., 2012). O consumo de dietas desequilibradas e substâncias ergogênicas, sem acompanhamento profissional, leva a distúrbios metabólicos, caracterizados pela falta ou excesso de nutrientes (Azevedo et al., 2011).

O tema da DM é de extrema relevância e carece de estudos que possibilitem identificar esse transtorno para que se possam traçar melhores métodos de terapêutica nutricional, haja vista que o impacto negativo desse distúrbio na alimentação, no estado nutricional e na saúde dos indivíduos é bastante significativo.

Levando isso em consideração, o objetivo deste trabalho foi identificar, entre praticantes de musculação, homens jovens com tendência à DM, e avaliar seu consumo diário de proteínas e lipídios.

\section{Metodologia}

Trata-se de uma pesquisa de campo, transversal, com abordagem quantitativa, executada no período de agosto a novembro de 2020, em duas academias de ginástica situadas na região metropolitana de Belo Horizonte, Minas Gerais (Silveira \& Córdova, 2009).

A amostra, definida por conveniência, foi composta de 30 homens de 18 a 45 anos, praticantes de musculação há pelo menos um ano, com frequência mínima de três vezes na semana. Os indivíduos foram abordados nos salões de musculação, nos períodos vespertino e noturno e convidados a participar da pesquisa mediante assinatura do termo de consentimento livre e esclarecido.

Foram excluídos os voluntários com qualquer tipo de desordem mental diagnosticada anteriormente, disfunções do sistema musculoesquelético que pudessem comprometer a prática de musculação ou doenças crônicas não transmissíveis que exigissem modificações no consumo alimentar ou pudessem acarretar alterações no peso corporal.

Os dados dos participantes referentes a idade, escolaridade, tempo de prática de musculação, frequência semanal, duração diária do treinamento e acompanhamento nutricional foram registrados em ficha de identificação.

Para identificar quais participantes possuíam tendência à DM, foi aplicado o Questionário do Complexo de Adônis (QCA), desenvolvido por Pope Junior et al. (2000/2000), constituído de 13 perguntas, com três alternativas de resposta cada. Esse questionário abordou o modo como as preocupações com a imagem corporal poderiam afetar o cotidiano de indivíduos acometidos com DM, contendo questões relacionadas ao tempo gasto com a checagem da aparência e com a prática de atividades destinadas a melhorá-la, ao consumo de alimentos ricos em proteínas e com baixos teores de gordura, ao uso de 
suplementos alimentares e esteroides anabolizantes, bem como aos impactos dessas inquietações na vida pessoal, acadêmica, financeira e laboral dos entrevistados.

As respostas dos participantes foram pontuadas da seguinte maneira: zero ponto para cada pergunta com resposta "a"; um ponto para cada pergunta com resposta "b"; três pontos para cada pergunta com resposta "c".

Os resultados do QCA consistiram na soma dos pontos obtidos em cada questão e os entrevistados foram classificados em quatro grupos distintos, consoante o grau de tendência ao desenvolvimento de DM: de zero a nove pontos, sem tendência, com preocupações menores com a imagem corporal; de 10 a 19, tendência branda a moderada, com preocupações que poderiam comprometer seriamente o dia a dia; de 20 a 29, tendência elevada, devendo ser considerada a busca por tratamento; de 30 a 39, provável diagnóstico de DM, a ser confirmado por profissional competente.

Os participantes que atingiram, no mínimo, 10 pontos e, portanto, apresentaram tendência à DM, tiveram a avaliação do consumo alimentar feita mediante a aplicação de recordatório alimentar de 24 horas (R24h), o qual contemplou as refeições realizadas no período do dia anterior ao da entrevista. O cálculo do R24h, para determinação da quantidade de proteínas e lipídios ingerida diariamente pelos entrevistados, foi feito utilizando-se o software Dietpro Clínico 6.1.

Com base nas recomendações da Sociedade Brasileira de Medicina do Esporte (SBME), foram consideradas normoproteicas as dietas que contemplaram o consumo diário de 1,6 a 1,7 gramas (g) de proteínas por quilo $(\mathrm{kg})$ de peso corporal - haja vista que os participantes praticavam exercícios de força com o objetivo de hipertrofia muscular -, e normolipídicas aquelas em que as calorias diárias derivadas de lipídios corresponderam a 30\% do valor calórico total (VCT) da dieta, com variação de 2,5\% para mais ou para menos (Hernandez \& Nahas, 2009).

O uso de suplementos alimentares pelos participantes foi descrito em campo específico do R24h, do qual constaram as seguintes informações: tipo de recurso ergogênico, frequência de utilização, quantidade consumida e responsável pela indicação. A composição nutricional dos suplementos foi computada no cálculo da ingestão alimentar.

Para aferição do peso corporal, foi utilizada uma balança profissional digital portátil (BK-200 FM Balmak®). Os voluntários foram posicionados no centro da balança, em posição ereta, com o peso distribuído em ambos os pés, sem adornos, sem sapatos e vestindo bermudas e camisetas adequadas à prática de atividade física.

$\mathrm{Na}$ análise dos dados, empregou-se estatística não paramétrica. As variáveis categóricas foram expressas como frequências e proporções. As variáveis contínuas foram expressas como média, desvio-padrão, mediana, mínimo e máximo. Para comparar as variáveis categóricas em relação aos grupos, foi utilizado o teste de qui-quadrado e, quando obtida frequência menor do que cinco, o teste exato de Fisher. Para comparar as variáveis contínuas em relação aos grupos, foram utilizados os testes de Mann-Whitney (duas categorias) e de Kruskal-Wallis (três categorias). As análises estatísticas foram realizadas no software STATA 12.0, considerando nível de significância de cinco por cento.

A pesquisa foi aprovada pelo Comitê de Ética em Pesquisa da Pontifícia Universidade Católica de Minas Gerais (CAAE 34453420.0.0000.5137) e respeitou todas as disposições da Resolução n. 466 (2012) do Conselho Nacional de Saúde, que regulamenta as pesquisas envolvendo seres humanos.

\section{Resultados e Discussão}

As características da amostra, atinentes à faixa etária e ao treino de musculação, estão apresentadas na Tabela 1. 
Tabela 1 - Idade dos participantes, tempo de prática de musculação, frequência semanal e duração diária do treino.

\begin{tabular}{lccccc}
\hline Variáveis & Média & Desvio-padrão & Mínimo & Mediana & Máximo \\
\hline Idade (anos) & 33,5 & 4,6 & 24,0 & 35,0 & 42,0 \\
Tempo de prática de musculação (anos) & 12,8 & 5,9 & 3,0 & 11,5 & 23,0 \\
Frequência semanal (dias) & 5,4 & 1,0 & 3,0 & 6,0 & 7,0 \\
Duração diária (minutos) & 69,7 & 21,6 & 40,0 & 60,0 & 130,0 \\
\hline
\end{tabular}

Fonte: Autores.

De acordo com a literatura, a DM acomete especialmente indivíduos do sexo masculino, com idades entre 16 e 35 anos, faixa etária em que o homem moderno assume o próprio corpo como sendo o principal instrumento de expressão no meio social (Camargo et al., 2008; Oliveira \& Mastrascusa, 2019).

Azevedo et al. (2012), ao realizarem um estudo com praticantes de musculação inscritos em comunidades virtuais dedicadas à DM, registraram uma média de idade de 19,6 \pm 1,9 anos. Resultado semelhante foi obtido por Zimmermann (2013), que observou a idade média de 24,9 \pm 4,1 anos ao investigar indícios de DM em praticantes de musculação da cidade de Biguaçu, Santa Catarina.

No presente estudo, a idade média dos participantes foi de 33,5 \pm 4,6 anos, semelhante à de outros estudos. É importante destacar que os entrevistados com as idades mínima (24 anos) e máxima (42 anos) apresentaram tendência à DM, deixando claro que se trata de um transtorno que afeta indivíduos em diferentes fases do ciclo da vida.

Em termos de escolaridade, quase a totalidade dos participantes $(93,4 \%)$ possuía ensino superior incompleto $(n=4)$, ensino superior completo $(n=15)$ ou pós-graduação $(n=9)$. Apenas um entrevistado possuía ensino fundamental e outro, ensino médio.

Esses resultados enfatizam que a DM não está relacionada à baixa escolaridade. Ao contrário, ela também acomete indivíduos com elevado grau de instrução e amplo acesso a informações, dos quais se espera a capacidade de analisar criticamente os conteúdos disponíveis nos meios de comunicação, bem como seu próprio comportamento. No estudo de Azevedo et al. (2012), a maioria dos participantes havia cursado ou estava cursando o ensino superior.

Indivíduos com DM praticam sessões extenuantes de musculação, evitam realizar atividades aeróbias e checam exaustivamente seus músculos no espelho, despendendo horas do dia com pensamentos relacionados à sua forma física (Olivardia, 2001).

Eles recusam participar de eventos sociais, esquivam-se de situações que possam acarretar exposição de seus corpos e chegam a usar várias camadas de roupas para parecerem ainda mais fortes (Pope Junior et al., 1997).

No que tange à prática de exercícios físicos, Azevedo et al. (2012) identificaram que metade dos entrevistados realizava treinamento de força há mais de três anos, cinco vezes por semana, durante sessões de uma hora e meia. No mesmo sentido, Zimmermann (2013) observou que adultos com indícios de DM praticavam musculação há cerca de dois ou três anos, enquanto Motter et al. (2017) revelaram que quase 60\% dos participantes treinavam há mais de quatro anos.

Nesta pesquisa, o tempo médio de prática de musculação foi de 12,8 $\pm 5,9$ anos, com frequência semanal de 5,4 $\pm 1,0$ dias, e duração diária de 69,7 \pm 21,6 minutos. A discrepância da média de tempo de prática de treinamento de força encontrada neste estudo em relação aos citados anteriormente pode ser explicada pelo fato de que os participantes desta pesquisa também apresentaram média de idade superior.

Ao analisar minuciosamente os dados, percebe-se que, em todos os trabalhos mencionados, os entrevistados começaram a praticar musculação por volta dos 20 anos de idade, período em que naturalmente os indivíduos começam a sentir-se insatisfeitos com o próprio corpo, sujeitando-se exageradamente ao treinamento de musculação, sem atribuir importância aos riscos à saúde decorrentes da busca incessante de um corpo extremamente musculoso (Azevedo et al., 2012). 
Em relação à identificação dos participantes com tendência à DM, o escore médio obtido no QCA foi de 11,9 $\pm 3,9$ pontos, demonstrando que a maioria dos entrevistados $(63,3 \%)$ apresentou tendência branda a moderada ao desenvolvimento do transtorno. É interessante frisar que nenhum dos voluntários foi classificado na faixa de possível diagnóstico de DM, conforme se observa no Gráfico 1.

Gráfico 1 - Classificação dos participantes, em termos percentuais, quanto à tendência ao desenvolvimento de DM.

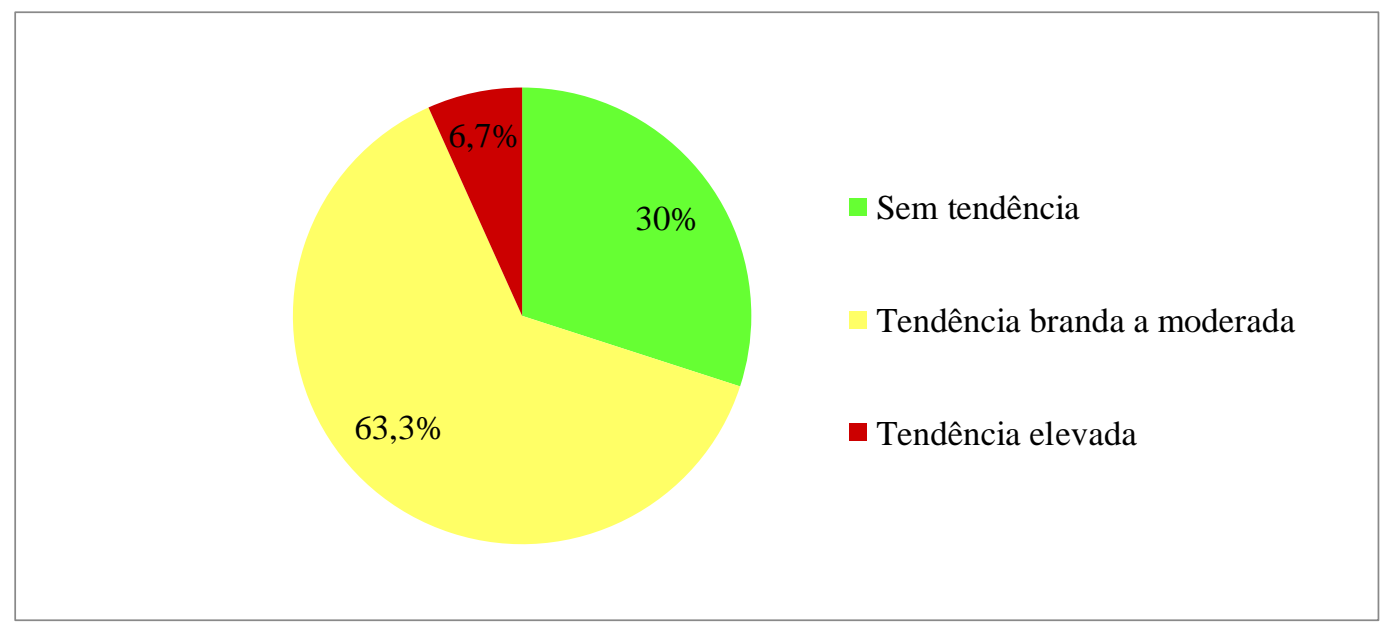

Fonte: Autores.

Chotao (2011), ao conduzir um estudo sobre a prevalência de DM entre praticantes de musculação matriculados em academias de Curitiba, Paraná, notou que, dos 40 entrevistados, 15 alunos $(62,5 \%)$ apresentavam tendência branda a moderada. No mesmo sentido, Pereira (2009), em uma pesquisa realizada com levantadores de peso da cidade do Porto, Portugal, identificou que 35 participantes $(41,7 \%)$ demonstravam risco brando a moderado de desenvolverem o transtorno.

Já no estudo de Motter et al. (2017), feito em Caxias do Sul, Rio Grande do Sul, 63,8\% dos entrevistados $(\mathrm{n}=37)$ possuíam tendência elevada à DM. Apenas no trabalho desenvolvido por Gomes et al. (2013), a maioria (53\%) dos voluntários não apresentou tendência à DM, mas vale ressaltar que $46 \%$ da amostra foram classificados na faixa de risco brando a moderado, servindo de alerta a proximidade entre os percentuais obtidos na pesquisa.

Ao comparar a idade, o tempo de prática de musculação, a frequência semanal e a duração diária do treinamento, levando em consideração a classificação dos entrevistados decorrente da aplicação do QCA, não foram encontradas diferenças significativas entre os grupos (Tabela 2). 
Tabela 2 - Comparação entre grupos em relação a idade, tempo de prática de musculação, frequência semanal e duração diária do treino.

\begin{tabular}{|c|c|c|c|c|c|c|}
\hline Variáveis & Tendência & Média & $\begin{array}{l}\text { Desvio- } \\
\text { padrão }\end{array}$ & Mínimo & Máximo & Valor-p \\
\hline \multirow[t]{3}{*}{ Idade (anos) } & Sem tendência & 32,7 & 5,3 & 25 & 38 & \multirow[t]{3}{*}{0,503} \\
\hline & Branda a moderada & 33,5 & 4,3 & 24 & 42 & \\
\hline & Elevada & 37,5 & 3,5 & 35 & 40 & \\
\hline \multirow{3}{*}{$\begin{array}{l}\text { Tempo de prática de } \\
\text { musculação (anos) }\end{array}$} & Sem tendência & 11,3 & 6,0 & 4 & 20 & \multirow[t]{3}{*}{0,396} \\
\hline & Branda a moderada & 13,2 & 5,9 & 3 & 23 & \\
\hline & Elevada & 16,0 & 7,1 & 11 & 21 & \\
\hline \multirow{3}{*}{$\begin{array}{l}\text { Frequência semanal } \\
\text { (dias) }\end{array}$} & Sem tendência & 4,9 & 1,3 & 3 & 6 & \multirow[t]{3}{*}{0,298} \\
\hline & Branda a moderada & 5,6 & 0,9 & 4 & 7 & \\
\hline & Elevada & 6,0 & 0 & 6 & 6 & \\
\hline \multirow{3}{*}{$\begin{array}{l}\text { Duração diária } \\
\text { (minutos) }\end{array}$} & Sem tendência & 63,9 & 24,0 & 40 & 120 & \multirow[t]{3}{*}{0,198} \\
\hline & Branda a moderada & 70,5 & 20,2 & 45 & 130 & \\
\hline & Elevada & 87,5 & 24,7 & 70 & 105 & \\
\hline
\end{tabular}

Fonte: Autores.

Floriano e D’Almeida (2016), ao avaliarem a prevalência de DM em homens adultos praticantes de musculação em academias de Itaqui, Rio Grande do Sul, também não encontraram diferenças significativas entre o tempo de academia dos participantes com ou sem indícios do transtorno.

Não obstante, é imprescindível destacar que, na presente pesquisa, os entrevistados com tendência elevada à DM apresentaram médias de idade, tempo de prática de musculação, frequência semanal e duração diária do treinamento superiores às dos participantes com tendência branda a moderada e dos que não demonstraram tendência a desenvolverem o transtorno, nessa respectiva ordem.

A literatura aponta, como traço marcante da alimentação de indivíduos com DM, a adoção de dietas hiperproteicas e hipolipídicas associadas ao consumo indiscriminado de suplementos alimentares, com o objetivo de aumentar a massa muscular e reduzir a gordura corporal (Cerea et al., 2018; Contesini et al., 2013).

Paula et al. (2014), ao avaliarem a ingestão alimentar de fisiculturistas residentes no estado de São Paulo, constataram um consumo bastante elevado de proteínas, correspondente a cerca de 4,0 g/kg/dia, por todos os atletas entrevistados.

Na pesquisa de Floriano e D’Almeida (2016), 54 participantes $(96,4 \%)$ apresentaram um consumo médio de proteínas de 2,6 g/kg/dia. Em um estudo realizado em Cascavel, Paraná, ficou demonstrado que a maioria (63,6\%) dos entrevistados consumia diariamente mais de 2,0 g de proteínas por kg de peso corporal (Oliveira et al., 2009). Praticantes de musculação de Alicante, Espanha, também ingeriam quantidades superiores de proteínas, em torno de 2,0 g/kg/dia, quando comparados aos entrevistados que não possuíam indícios do transtorno (Segura et al., 2015).

A SBME esclarece que o consumo acima de 1,6 a 1,7 g de proteínas por kg de peso corporal por dia, por indivíduos que praticam exercícios de força com o objetivo de hipertrofia muscular, não contribui para um aumento adicional de massa magra, uma vez que os tecidos corporais possuem um limite para a absorção de proteínas (Hernandez \& Nahas, 2009).

Nesse sentido, Morton et al. (2018), ao escreverem uma revisão sistemática sobre os efeitos da suplementação de proteínas sobre os ganhos de massa muscular e de força resultantes da prática de exercícios resistidos, chegaram à conclusão de que a ingestão proteica de $1,6 \mathrm{~g} / \mathrm{kg} /$ dia é suficiente para auxiliar no processo de hipertrofia muscular, principalmente no caso de indivíduos jovens. 
É bastante usual apontar a disfunção renal como sendo a principal consequência do consumo prolongado de dietas hiperproteicas. Em revisão de literatura, Severo et al. (2018) observaram que faltam evidências científicas que comprovem que o consumo aumentado de proteínas resultaria em deterioração progressiva do funcionamento renal em indivíduos saudáveis. Não obstante, pessoas que já apresentam algum comprometimento na atividade renal devem ser cautelosas em relação à ingestão diária desse macronutriente (Kalantar-Zadeh et al., 2020; Severo et al., 2018).

Cumpre enfatizar que dietas desequilibradas, nas quais se tem um aumento exagerado do consumo proteico, acabam apresentando, como consequência, uma restrição lipídica excessiva, em virtude da distribuição equivocada dos macronutrientes. Isso ficou comprovado na pesquisa de Paula et al. (2014), na qual a ingestão de proteínas representou, em média, $40 \%$ do VCT das dietas analisadas, ao passo que o consumo médio de lipídios, somente 18,9\%.

De acordo com a SBME, indivíduos adultos saudáveis necessitam de aproximadamente um grama de gordura por quilo de peso corporal por dia, o que equivale a cerca de 30\% do VCT da dieta, recomendação que tem prevalecido igualmente para praticantes de exercício físico (Hernandez \& Nahas, 2009).

No presente estudo, dos 21 entrevistados que apresentaram tendência branda a moderada ou elevada à DM, 16 (76,2\%) consumiam dietas hiperproteicas, sendo que apenas três participantes $(14,3 \%)$ consumiam dietas normoproteicas e dois $(9,5 \%)$, hipoproteicas. A ingestão média diária de proteínas foi de $2,7 \pm 1,0 \mathrm{~g} / \mathrm{kg}$, com mínimo de $1,4 \mathrm{~g} / \mathrm{kg}$, máximo de 5,0 $\mathrm{g} / \mathrm{kg}$ e mediana de $2,7 \mathrm{~g} / \mathrm{kg}$, o que revela um consumo proteico bastante superior ao recomendado pela SBME.

No que tange à fração lipídica, constatou-se que 18 (85,7\%) participantes consumiam dietas hipolipídicas. É importante salientar que nenhum entrevistado apresentou consumo adequado de lipídios, ao passo que três $(14,3 \%)$ informaram uma ingestão acima da ideal. A média de calorias diárias derivadas desse macronutriente correspondeu a 22,9 $\pm 5,7 \%$ do VCT, com mínimo de $14,6 \%$, máximo de $34,4 \%$ e mediana de $21,1 \%$.

Ao comparar o consumo de proteínas e de lipídios dos participantes com tendência branda a moderada à DM ao daqueles com tendência elevada a desenvolvê-la, não foram encontradas diferenças significativas (tabela 3).

Tabela 3 - Comparação entre a classificação quanto à tendência ao desenvolvimento de DM e o consumo diário de proteínas e de lipídios.

\begin{tabular}{llccccc}
\hline Variáveis & Tendência & Média & $\begin{array}{c}\text { Desvio- } \\
\text { padrão }\end{array}$ & Mínimo & Máximo & Valor-p \\
\hline Proteínas & Branda a moderada & 2,6 & 0,9 & 1,4 & 5,0 & 0,308 \\
& Elevada & 3,6 & 1,3 & 2,7 & 4,5 & \\
\multirow{2}{*}{ Lipídios } & Branda a moderada & 25,9 & 12,0 & 17,4 & 34,4 & 0,811 \\
& Elevada & 22,6 & 5,2 & 14,6 & 34,2 & \\
\hline
\end{tabular}

Fonte: Autores.

Entretanto, notou-se que os participantes com tendência elevada à DM consumiam quantidades superiores de proteínas e eram adeptos de dietas com percentuais inferiores de lipídios, quando comparados aos entrevistados com tendência branda a moderada.

Nesta pesquisa, não houve associação entre o consumo de dietas hipoproteicas, normoproteicas ou hiperproteicas e o grau de tendência ao desenvolvimento de DM $(\mathrm{p}=0,708)$, tampouco entre o consumo de dietas hipolipídicas, normolipídicas ou hiperlipídicas e o grau de tendência ao desenvolvimento do transtorno $(\mathrm{p}=0,129)$.

Embora a suplementação alimentar seja indicada apenas nos casos em que não se faz possível atingir as necessidades nutricionais por meio da ingestão de alimentos, a sua utilização indiscriminada tem se tornado cada vez mais frequente entre praticantes de musculação (Contesini et al., 2013). 
Quando da coleta dos dados referentes ao consumo alimentar, 71,4\% dos participantes $(\mathrm{n}=15)$ revelaram fazer uso de suplementos alimentares, sobretudo daqueles à base de proteínas e aminoácidos, como proteína do soro do leite (whey protein), albumina, creatina e aminoácidos de cadeia ramificada (BCAA).

Na pesquisa conduzida por Azevedo et al. (2012), 90\% dos voluntários relataram consumir suplementos alimentares, ao passo que, no estudo de Paula et al. (2014), a prevalência do uso desses recursos ergogênicos atingiu nível ainda maior, alcançando $100 \%$ dos entrevistados.

No mesmo sentido, Trog e Teixeira (2009) identificaram que 39\% dos frequentadores de quatro academias de ginástica de Irati, Paraná, utilizavam suplementos alimentares, especialmente aqueles com conteúdo proteico (84\%).

Em uma pesquisa realizada em Ubá, Minas Gerais, com praticantes de musculação do sexo masculino, Sperandio et al. (2017) constataram que 76,3\% dos avaliados consumiam suplementos alimentares, sendo que 44,4\% deles faziam uso contínuo dessas substâncias, por indicação dos próprios professores das academias de ginástica (48,9\%), sem a supervisão de nutricionistas.

No presente estudo, ficou evidenciado que $46,7 \%$ dos entrevistados que consumiam suplementos alimentares $(n=7)$ não eram acompanhados por nutricionistas, tendo decidido ingeri-los por conta própria, depois de realizarem pesquisas na rede mundial de computadores, ou após terem sido influenciados por amigos, familiares, instrutores de musculação e vendedores de lojas especializadas, ao argumento de que essas substâncias, isoladamente, seriam capazes de proporcionar aumento da massa muscular e diminuição da gordura corporal.

A maioria dos entrevistados $(n=20)$ afirmou não se consultar com nutricionistas. Porém, houve associação entre apresentar tendência branda a moderada à DM e ter acompanhamento nutricional, assim como entre não ter tendência a desenvolver o transtorno e não ter acompanhamento nutricional, conforme descrito na Tabela 4.

Tabela 4 - Associação entre a classificação quanto à tendência ao desenvolvimento de DM e acompanhamento nutricional.

\begin{tabular}{|c|c|c|c|c|}
\hline Variável & Sem tendência & $\begin{array}{c}\text { Tendência branda a } \\
\text { moderada }\end{array}$ & Tendência elevada & Valor-p \\
\hline \multicolumn{5}{|c|}{ Acompanhamento nutricional } \\
\hline Não & 8 & 12 & 0 & $0,047 *$ \\
\hline Sim & 1 & 7 & 2 & \\
\hline
\end{tabular}

Legenda: * Teste de qui-quadrado com nível de significância de 5\%. Fonte: Autores.

Esses dados mostram que indivíduos com DM costumam consultar-se com nutricionistas, em virtude da busca obsessiva de um corpo escultural, marcado notadamente por músculos volumosos e definidos.

É fundamental a participação do nutricionista no tratamento de distúrbios associados a distorções da imagem corporal, tendo em vista que esses transtornos resultam em profundas alterações no consumo, padrão e comportamento alimentares (Latterza et al., 2004).

Acentua-se, portanto, a importância de que esse profissional possua conhecimento para identificar precocemente o transtorno e, assim, poder definir os melhores métodos de tratamento. Latterza et al. (2004) salientam que o trabalho do nutricionista nessa área requer competências não inerentes à sua formação, como conhecimentos de psicologia, psiquiatria e terapia cognitivo-comportamental.

Alencar et al. (2020) e Motter et al. (2013) deixam clara a indispensabilidade de um trabalho em conjunto com outros profissionais da saúde, a exemplo de médicos, psicólogos e educadores físicos. Somente assim, diante de um transtorno tão complexo, multifatorial e com repercussões em diferentes esferas da vida, será possível minimizar os riscos à saúde 
decorrentes do excesso de exercícios físicos, da adoção de práticas alimentares inadequadas e do uso indiscriminado de suplementos alimentares.

Os resultados desta pesquisa fornecem dados significativos acerca da prevalência de DM entre homens jovens praticantes de musculação e possibilita avaliar o padrão dietético adotado por indivíduos acometidos pelo transtorno, especificamente no que tange ao consumo de proteínas, lipídios e suplementos alimentares.

\section{Conclusão}

Os dados deste estudo revelaram que 63,3\% dos participantes apresentaram tendência branda a moderada à DM, ao passo que $6,7 \%$ demonstraram tendência elevada ao desenvolvimento do transtorno.

No que tange ao padrão dietético, concluiu-se que 76,2\% dos entrevistados com tendência à DM consumiam dietas hiperproteicas e, $85,7 \%$, dietas hipolipídicas.

Em relação ao consumo de suplementos alimentares, $71,4 \%$ dos participantes com tendência ao transtorno relataram fazer uso dessas substâncias, sendo que, entre eles, 46,7\% não eram acompanhados por nutricionistas.

Foi encontrada associação entre apresentar tendência branda a moderada à DM e ter acompanhamento nutricional, assim como entre não ter tendência a desenvolver o transtorno e não ter acompanhamento nutricional.

Reforçou-se, assim, a importância de os nutricionistas possuírem conhecimento técnico sobre DM para identificar precocemente a tendência de seus pacientes a desenvolverem o transtorno e, por conseguinte, poderem definir os melhores métodos de abordagem terapêutica nutricional. Dessa maneira, será possível diminuir os prejuízos à saúde resultantes da prática excessiva de musculação, da adoção de padrões alimentares desequilibrados e do consumo indiscriminado de suplementos alimentares por indivíduos com DM. Deve-se frisar que a atividade física regular e a alimentação saudáveis constituem estratégias primordiais para a qualidade de vida, cujo equilíbrio ocupa posição de destaque no processo saúdedoença.

Sugere-se que novos estudos sejam realizados para avaliar o uso de esteroides anabolizantes por indivíduos com tendência à DM, uma vez que a utilização dessas substâncias, sem a supervisão de profissionais habilitados, também é um traço marcante do transtorno em questão.

\section{Referências}

Alencar, A. S., Nascimento, L., Soares, C. F., Beserra, M., \& Brito, N. L. (2020). Vigorexy: A danger in the search of the ideal body. The International Journal of Social Psychiatry, 20764020927045.

American Psychiatric Association. (2014). Manual diagnóstico e estatístico de transtornos mentais: DSM-5 (Nascimento, M. I. C. et al., Trad, Cordioli, A. V. et al. Rev. Técnica). Artmed. (Trabalho original publicado em 2013)

Assunção, S. S. M. (2002). Dismorfia muscular. Revista Brasileira de Psiquiatria, 24(3), 80-84.

Azevedo, A. M. P., Ferreira, A. C. D., Silva, P. P. C., Silva, E. A. P. C., \& Caminha, I. O. (2011). Dismorfia muscular: Características alimentares e da suplementação nutricional. Revista ConScientiae Saúde, 10(1), 129-137.

Azevedo, A. P., Ferreira, A. C., Silva, P. P., Caminha, I. O., \& Freitas, C. M. (2012). Dismorfia muscular: A busca pelo corpo hipermusculoso. Motricidade, $8(1), 53-66$.

Bégin, C., Turcotte, O., \& Rodrigue, C. (2019). Psychosocial factors underlying symptoms of muscle dysmorphia in a non-clinical sample of men. Psychiatry Research, 272, 319-325.

Bonfim, G. W., Nascimento, I. P. C., \& Borges, N. B. (2016). Transtorno dismórfico corporal: Revisão da literatura. Contextos Clínicos, 9(2), $240-252$.

Camargo, T. P. P., Costa, S. P. V., Uzunian, L. G., \& Viebig, R. F. (2008). Vigorexia: Revisão dos aspectos atuais deste distúrbio de imagem corporal. Revista Brasileira de Psicologia do Esporte, 2(1), 1-15.

Cerea, S., Bottesi, G., Pacelli, Q. F., Paoli, A., \& Ghisi, M. (2018). Muscle dysmorphia and its associated psychological features in three groups of recreational athletes. Scientific Reports, 8(1), 1-8. 
Chotao, S. L. (2011). A incidência de vigorexia em alunos de musculação de academias de Curitiba - PR [Monografia, Universidade Tuiuti do Paraná].

Chung, B. (2001). Muscle dysmorphia: A critical review of the proposed criteria. Perspectives in Biology and Medicine, 44(4), 565-574.

Cohane, G. H., \& Pope Junior, H. G. (2001). Body image in boys: A review of the literature. International Journal of Eating Disorders, $29(4), 373-379$.

Contesini, N., Adami, F., Blake, M. T., Monteiro, C. B. M., Abreu, L. C., Valenti, V. E., Almeida, F. S., Luciano, A. P., Cardoso, M. A., Benedet, J., Vasconcelos, F. A. G., Leone, C., \& Frainer, D. E. S. (2013). Nutritional strategies of physically active subjects with muscle dysmorphia. International Archives of Medicine, 6(25), 1-6.

Fernandes Filho, A. (2010). Breve histórico da beleza masculina. Moda Palavra, 3(6), 59-79.

Ferreira, M. E. C., Castro, A. P. A., \& Gomes, G. A. (2005). Obsessão masculina pelo corpo: Malhado, forte e sarado. Revista Brasileira de Ciências do Esporte, 27(1), 167-182.

Floriano, J. M., \& D’Almeida, K. S. (2016). Prevalência de transtorno dismórfico muscular em homens adultos residentes na fronteira oeste do Rio Grande do Sul. Revista Brasileira de Nutrição Esportiva, 10(58), 448-457.

Gomes, R. L., Gonzaga, J. L. D., Guedes, A. R. L. A., Gomes, C. L., Machado, A. A. N., Ceccatto, V. M., \& Soares, P. M. (2013). Correlação entre o Questionário do Complexo de Adônis (QCA) com fatores do Questionário de Dependência ao Exercício Físico (QDEF) em praticantes de musculação na cidade de Fortaleza - CE. Coleção Pesquisa em Educação Física, 12(4), 93-100.

Grieve, F. G. (2007). A conceptual model of factors contributing to the development of muscle dysmorphia. Eating Disorders, 15(1), 63-80.

Hernandez, A. J., \& Nahas, R. M. (2009). Modificações dietéticas, reposição hídrica, suplementos alimentares e drogas: Comprovação de ação ergogênica e potenciais riscos para a saúde. Revista Brasileira de Medicina do Esporte, 15(3), 3-12.

Jornal Estado de Minas. (2019). Por que as academias de ginástica estão malhando também? https://www.em.com.br/app/noticia/economia/2019/08/18/internas_economia,1078035/porque-as-academias-de-ginastica-estao-malhando-tambem.shtml.

Kalantar-Zadeh, K., Kramer, H. M., \& Fouque, D. (2020). High-protein diet is bad for kidney health: Unleashing the taboo. Nephrology Dialysis Transplantation, 35(1), 1-4.

Kotona, E. A. W., Oliveira, F. B., Silva, L. A., Salvador, A. A., Rossetti, F. X., Tamasia, G. A., Vicentini, M. S., \& Bello, S. R. B. (2018). Vigorexia e suas correlações nutricionais. Research, Society and Development, 7(1), 1-11.

Latterza, A. R., Dunker, K. L. L., Scagliusi, F. B., \& Kemen, E. (2004). Tratamento nutricional dos transtornos alimentares. Revista de Psiquiatria Clínica, 31(4), 173-176.

Morton, R. W., Murphy, K. T., McKellar, S. R., Schoenfeld, B. J., Henselmans, M., Helms, E., Aragon, A. A., Devries, M. C., Banfield, L., Krieger, J. W., \& Phillips, S. M. (2018). A systematic review, meta-analysis and metaregression of the effect of protein supplementation on resistance training-induced gains in muscle mass and strength in healthy adults. British Journal of Sports Medicine, Vol. 52, 376-384.

Motter, A. G., Bellini, M., \& Almeida, S. (2017). Incidência de vigorexia em praticantes de musculação. Do Corpo: Ciências e Artes, 7(1), 117-127.

Olivardia, R. (2001). Mirror, mirror on the wall, who's the largest of them all? The features and phenomenology of muscle dysmorphia. Harvard Review of Psychiatry, 9(5), 254-259.

Oliveira, A. F., Fatel, E. C. S., Soares, B. M., \& Círico, D. (2009). Avaliação nutricional de praticantes de musculação com objetivo de hipertrofia muscular do município de Cascavel - PR. Colloquium Vitae, 1(1), 44-52.

Oliveira, F. S. S. C., \& Mastrascusa, C. L. (2019). Vigorexia em praticantes masculinos do treinamento de força entre 18-35 anos. Revista Ciência em Movimento, 21(42), 3-15.

Paula, B. B., Sarrassini, F. B., Tonello, M. G. M., Neiva, C. M., \& Manochio, M. G. (2014). Avaliação do consumo alimentar e percepção da imagem corporal de culturistas. Lecturas Educación Física y Deportes, 19(193), 1-9.

Pereira, I. A. T. S. (2009). A vigorexia e os esteroides anabolizantes androgênios em levantadores de peso [Monografia, Universidade do Porto].

Pope Junior, H. G., Gruber, A. J., Choi, P., Olivardia, R., \& Phillips, K. A. (1997). Muscle dysmorphia: An underrecognized form of body dysmorphic disorder. Psychosomatics, 38(6), 548-557.

Pope Junior, H. G., Katz, D. L., \& Hudson, J. I. (1993). Anorexia nervosa and "reverse anorexia" among 108 male bodybuilders. Comprehensive Psychiatry, 34(6), 406-409.

Pope Junior, H. G., Phillips, K. A., \& Olivardia, R. (2000). Você tem o Complexo de Adônis? Dois testes e seus espantosos resultados. In H. G. Pope Junior, K. A. Phillips, \& R. Olivardia, O Complexo de Adônis: A obsessão masculina pelo corpo (S. Teixeira, Trad., pp. 88-110). Campus. (Trabalho original publicado em 2000)

Resolução n. 466, de 12 de dezembro de 2012. (2013). Dispõe sobre diretrizes e normas regulamentadoras de pesquisas envolvendo seres humanos. Conselho Nacional de Saúde.

Segura, A. M., Castell, E. C., Baeza, M. M. R., \& Guillén, V. F. G. (2015). Valoración de la dieta de usuarios de sala de musculación con dismorfia muscular (vigorexia). Nutricion Hospitalaria, 32(1), 324-329.

Severo, P. R. F., Borges, V. S., Moraes, M. F. L., Magalhães, G. A., Lemos, E. J., David, L. M. M., Losekann, A., \& Silva, J. L. B. (2018). Dieta hiperproteica e função renal: Discutindo seus efeitos em adultos normais. Acta Medica - Ligas acadêmicas, 39(1), $247-257$. 
Research, Society and Development, v. 10, n. 5, e2710514501, 2021

(CC BY 4.0) | ISSN 2525-3409 | DOI: http://dx.doi.org/10.33448/rsd-v10i5.14501

Silveira, D. T., \& Córdova, F. P. (2009). A pesquisa científica. In T. E. Gerhardt, \& D. T. Silveira (Org.), Métodos de pesquisa (pp. 31-42). Editora da UFRGS.

Soler, P. T., Fernandes, H. M., Damasceno, V. O., \& Novaes, J. S. (2013). Vigorexia e níveis de dependência de exercício em frequentadores de academias e fisiculturistas. Revista Brasileira de Medicina do Esporte, 19(5), 343-348.

Sperandio, B. B., Silva, L. D. S., Domingues, S. F., Ferreira, E. F., \& Oliveira, R. A. R. (2017). Consumo de recursos ergogênicos e suplementos alimentares por homens nas academias de musculação em Ubá - MG. Revista Brasileira de Nutrição Esportiva, 11(63), 375-382.

Trog, S. D., \& Teixeira, E. (2009). Uso de suplementação alimentar com proteínas e aminoácidos por praticantes de musculação do município de Irati - PR. Cinergis, 10(1), 43-53.

Velozo, D. L. F. G., Reis, M. A. I., Landim, L. M., \& Silva, T. D. R. (2020). Vigorexia: Dismorfia corporal. Revista Científica Multidisciplinar Núcleo do Conhecimento, 5(10), 72-82.

White, E. K., Mooney, J., \& Warren, C. S. (2019). Ethnicity, eating pathology, drive for muscularity, and muscle dysmorphia in college men: A descriptive study. Eating Disorders, 27(2), 137-151.

Zimmermann, F. (2013). Indícios de vigorexia em adultos jovens praticantes de musculação em academias de Biguaçu - SC [Trabalho de Conclusão de Curso, Universidade Federal de Santa Catarina]. 